Research Journal of Applied Sciences 7 (2): 60-65, 2012

ISSN: $1815-932 \mathrm{X}$

(C) Medwell Journals, 2012

\title{
Evaluation of Multiregional Fuzzy-Based pH Cascade Control with ANFIS-Based pH Observer
}

\author{
Shebel A. AlSabbah, Mohammad A. Al-Khedher and Tariq M. Younes \\ Department of Mechatronics, Faculty of Engineering and Technology, \\ Al Balqa Applied University, P.O. Box 15008, 11134 Amman, Jordan
}

\begin{abstract}
In} \mathrm{pH}$ reactors, determination and control of $\mathrm{pH}$ is a common problem concerning chemical-based industrial processes due to the non-linearity observed in the titration curve. The researchers introduced a modified multiregional Fuzzy-Based Control System to overcome the complexity of precise control of $\mathrm{pH}$. In order to compensate for the experimental inaccuracies in measurements of $\mathrm{pH}$ in-situ values; an observer for $\mathrm{pH}$ is implemented using Adaptive Neuro-Fuzzy Inference System (ANFIS). The $\mathrm{pH}$ control approach and ANFIS-based observer are integrated in a nonlinear cascade structure to ensure the dynamic modifications and stability enhancement. The cascade structure is designed using a multiregional fuzzy PI controller in the master loop and a Wiener Model-based fuzzy proportional controller as a slave one. The Multiregional Fuzzy Cascade Control (MFCC) structure is developed to implicate the three main regions of the titration curve.
\end{abstract}

Key words: Titration process, cascade structure, multiregional fuzzy, ANFIS, $\mathrm{pH}$ observer, Jordan

\section{INTRODUCTION}

$\mathrm{pH}$ control had always drawn attention of chemical engineers because of its significance in various fields as medicine where the effect of $\mathrm{pH}$ on the enzymes and blood is intensely investigated and the industry which is concerned with manufacturing of textile dyes and bleach products.

Furthermore, several studies had enriched this research area as environmentalists concerns regarding treating waste water and the acidic rain and recently the enormous interest of the nuclear scientists to gain a safe monitoring of the $\mathrm{pH}$ in the nuclear reactors and resulted materials (Luyben, 1989).

In such systems, a fundamental concern is the vast variation of $\mathrm{pH}$ encountered with titration process; this implies that a small change in the composition specifications in the process could lead to great divergence in $\mathrm{pH}$ values which endanger the stability of the system. This arouses curiosity of researchers and engineers who investigated the development of empirical models and proposed various control techniques to be applied with industrial $\mathrm{pH}$ processes.

Recent studies on the application of Wiener Model-based controller considered a measurement delay and proposed an Adaptive Control System for $\mathrm{pH}$ control using neural networks. It was introduced as a cascade structure to maintain $\mathrm{pH}$ at 7 when the titration curve undergoes large variations. The Cascade System consists of an inner loop which includes a Typical Wiener Model with a proportional controller while the outer loop is a conventional feedback system with a Proportional and Integral (PI) controller.

This model had overcome the large oscillations complication resulted from the switching over titration curve from weak to strong acid and vice versa, nevertheless it has some drawbacks with large variations of $\mathrm{pH}$.

Therefore, this study proposes a Multiregional Fuzzy-Based Cascade Control System; this approach is accomplished by sectioning the titration curve into three main regions in order to encounter the large variations of $\mathrm{pH}$ by ensuring stability improvements.

Evaluation of $\mathrm{pH}$ as a controlled variable is achieved using an adaptive neuro-fuzzy based $\mathrm{pH}$ observer which is validated within the master feedback loop of the proposed control structure as shown in Fig. 1. The models are designed and verified numerically with MATLAB/SIMULINK to obtain the optimum design for the neutralization process under study.

Corresponding Author: Shebel A. AlSabbah, Department of Mechatronics, Faculty of Engineering Technology, Al Balqa Applied University, P.O. Box 15008, 11134 Amman, Jordan 


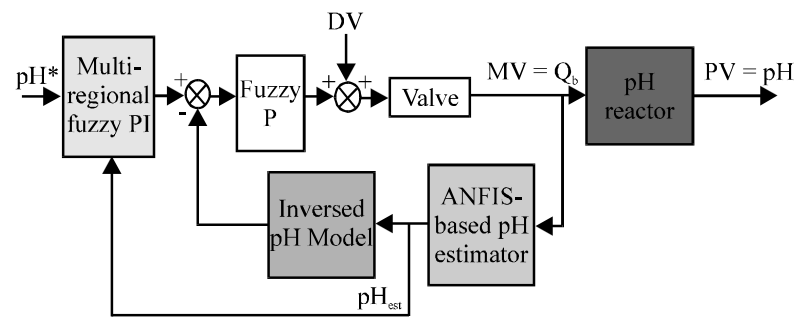

Fig. 1: Multiregional fuzzy-based cascade control structure where $\mathrm{pH}^{*}$ is the reference value of $\mathrm{pH}$, DV is the Disturbance Variable affecting the control signal, MV is the Manipulated Variable of the system (flow of base $\mathrm{L} / \mathrm{min}$ ), $\mathrm{PV}$ is the measured Process Variable $(\mathrm{pH})$ and $\mathrm{pH}_{\text {est }}$ is the estimated $\mathrm{pH}$ by the proposed ANFIS observer

\section{INVERSE pH MODELING}

The titration curve can describe the nonlinearity of the $\mathrm{pH}$ process as shown in Fig. 2. The curve starts with a linear behavior at the initial region afterwards, the nonlinear behavior is initiated in the second region where a slight difference in volume or flow rate of the base will lead to a great variation of $\mathrm{pH}$ values.

The sudden variation of the $\mathrm{pH}$ in the second region of the titration curve could endanger the stability of the control system which is designed to maintain $\mathrm{pH}$ at a reference point. On the other hand, alternating from weak to strong acid or vice versa could cause instability of the process.

This is due to the huge variations of the steady state gain endured in the switching process, (the gain of the strong acid at steady state is 350 times the weak acid gain) as noted by Luyben (1989), Magada (2008) and Ogunnaik and Ray (1994).

Obtaining the titration curve for a weak/strong acid strong base is a challenging procedure since, the titration curve consists of several regions that behave in a different manner according to the $\left[\mathrm{H}^{+}\right]$in the solution. The titration operation is shown in Fig. 3. Equation 1 and 2 illustrates the volumetric concentration changes for acid and base streams:

$$
\begin{aligned}
& \mathrm{V} \frac{\mathrm{dc} \mathrm{c}_{\mathrm{za}}}{\mathrm{dt}}=\mathrm{Q}_{\mathrm{a}} \mathrm{C}_{\mathrm{a}}-\left(\mathrm{Q}_{\mathrm{a}}+\mathrm{Q}_{\mathrm{b}}\right) \mathrm{c}_{\mathrm{za}} \\
& \mathrm{V} \frac{\mathrm{dc_{ \textrm {zb } }}}{\mathrm{dt}}=\mathrm{Q}_{\mathrm{b}} \mathrm{C}_{\mathrm{b}}-\left(\mathrm{Q}_{\mathrm{a}}+\mathrm{Q}_{\mathrm{b}}\right) \mathrm{c}_{\mathrm{zb}} \\
& -\mathrm{kc}_{\mathrm{za}}+\mathrm{c}_{\mathrm{zb}}+10^{-\mathrm{pH}}-10^{\mathrm{pH}-14}=0
\end{aligned}
$$

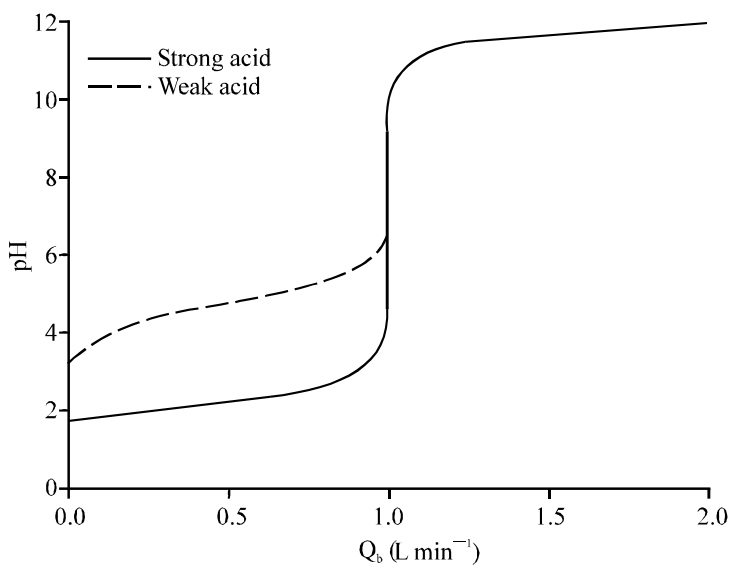

Fig. 2: Titration curves for strong/weak acid-strong base

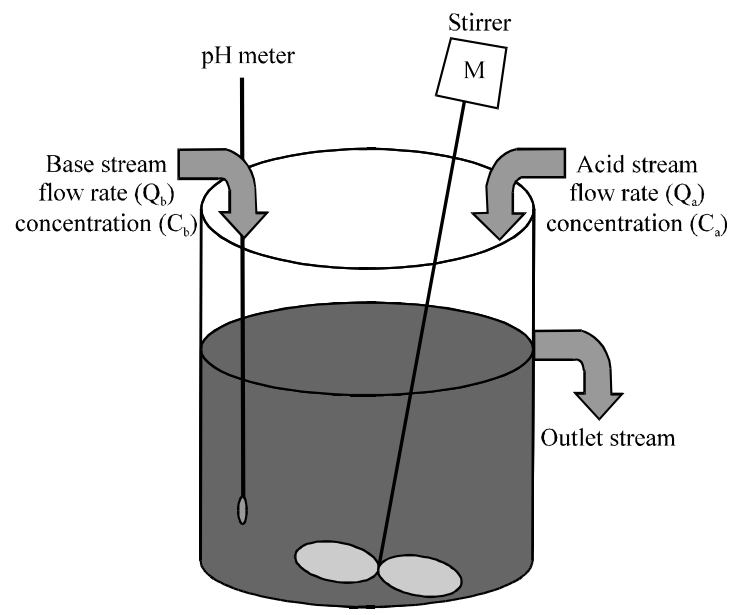

Fig. 3: $\mathrm{pH}$ reactor schematic

Where:

$\mathrm{c}_{\mathrm{za}}$ and $\mathrm{c}_{\mathrm{zb}}=$ The concentration values of acid and base in the outlet stream

$\mathrm{Q}_{\mathrm{a}}$ and $\mathrm{Q}_{\mathrm{b}}=$ The volumetric flow rates of acid and base entering the reactor

$\mathrm{V}=$ The reactor volume

$\mathrm{k}=\mathrm{A}$ constant indicates the strength of acid entering the reactor and given as:

For strong acid-strong base:

$$
\mathrm{k}=1
$$

For weak acid:

$$
\mathrm{k}=\frac{1}{\left(1+10^{\left(\mathrm{pK}_{\mathrm{a}}-\mathrm{pH}\right)}\right)}
$$

where, $\mathrm{K}_{\mathrm{a}}$ is the acid dissociation constant:

$$
\mathrm{pK}_{\mathrm{a}}=-\log _{10}\left(\mathrm{~K}_{\mathrm{a}}\right)
$$


at steady state condition where both derivatives of $\mathrm{c}_{\mathrm{xa}}, \mathrm{c}_{\mathrm{zb}}$ is substituted as zero. By solving Eq. 1 and 2 for $\mathrm{c}_{\mathrm{x} a} \mathrm{c}_{\mathrm{xb}}$ values and substitute it in Eq. 3 we will get:

$$
\frac{-\mathrm{kQ}_{\mathrm{a}} \mathrm{C}_{\mathrm{a}}}{\mathrm{Q}_{\mathrm{a}}+\mathrm{Q}_{\mathrm{b}}}+\frac{\mathrm{Q}_{\mathrm{b}} \mathrm{C}_{\mathrm{b}}}{\mathrm{Q}_{\mathrm{a}}+\mathrm{Q}_{\mathrm{b}}}+10^{-\mathrm{pH}}-10^{\mathrm{pH}-14}=0
$$

From Eq. 6, $\mathrm{Q}_{b}$ could be obtained, simply as:

$$
\mathrm{Q}_{\mathrm{b}}=\mathrm{Q}_{\mathrm{a}} \frac{\mathrm{kc}_{\mathrm{a}}-10^{-\mathrm{pH}}+10^{\mathrm{pH}-14}}{\mathrm{c}_{\mathrm{b}}+10^{-\mathrm{pH}}-10^{\mathrm{pH}-14}}
$$

Solve for the titration curve in the form of $\mathrm{pH}=\mathrm{f}\left(\mathrm{Q}_{\mathrm{b}}\right)$ :

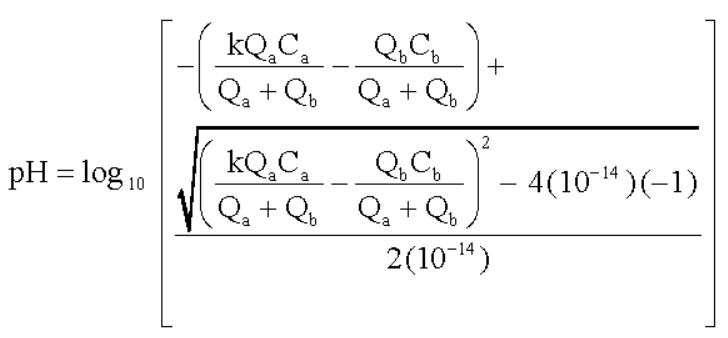

Equation 8 evaluates $\mathrm{pH}$ values according to the variation of the $\mathrm{Q}_{b}$ and consequently produces the titration curve for strong/weak acid-strong base. For the strong acid system, the titration process is simpler because of large dissociation constant which is responsible for the dissociation of the entire amount of acid into ions to be consumed by the disassociated base ions to form the simple molecules of salt and water.

Assuming that: $\mathrm{C}_{\mathrm{a}}=0.02\left[\mathrm{~mol} \mathrm{~L}^{-1}\right]$ for weak and strong acid, $\mathrm{C}_{\mathrm{b}}=0.025\left[\mathrm{~mol} \mathrm{~L}^{-1}\right], \mathrm{Q}_{\mathrm{a}}=1.25\left[\mathrm{~L} \mathrm{~min}^{-1}\right]$ and $\mathrm{K}_{\mathrm{a}}=\infty$ for strong acid. The small dissociation constant of the weak acid prevents the base from consuming an equal amount from the weak acid due to incomplete disassociation of the weak acid into an acid ions (base conjugate) and hydrogen ions

The titration curve of the weak acid system is obtained by substituting $\left(\mathrm{K}_{\mathrm{a}}\right)$ of the weak acid $\left(\mathrm{K}_{\mathrm{a}}=1.83 \times 10^{-5}\right)$. Figure 2 shows the obtained titration curves of Eq. 8 for weak/strong acid-strong base.

Figure 2 shows the difference in titration curve between weak acid system and a strong acid system. It worth to mention that the weak acid titration curve is smoother as shown in this figure, this is due to what is called as the Buffering effect (Parekh et al., 1994; Pishvaie and Shahrokhi, 2006).

\section{DESIGN OF ADAPTIVE NEURO-FUZZY pH OBSERVER}

The ANFIS observer is an empirical model designed to replace the $\mathrm{pH}$ meter. The designed ANFIS Model attempts to match nonlinearities and parametric uncertainties encountered with such dynamic process (Pishvaie and Shahrokhi, 2006; Qin and Borders, 1994; Shinskey, 1974) and it has been proposed also to overcome the typical difficulties faced with using $\mathrm{pH}$ meters in chemical plants as wiring issues, troubleshooting and maintenance of the system. The proposed observer requires an evaluation of all variables that might affect the $\mathrm{pH}$.

The fuzzy inference process is implemented as a generalized neural network which is then adjusted by a combination of least squares estimation and backpropagation algorithm (Vojtesek and Dostal, 2005; Gulaian and Lane, 1990). The fuzzy rules and the range of the membership functions are optimized to minimize the output error between the output of the Fuzzy Model and the input data. Figure 4 shows the architecture of the implemented five-layer ANFIS System of Sugeno type (Guner, 2003; Gupta et al., 2009). The first layer is the input layer, the 2-input vectors are shown in Fig. 4; $x_{1}: Q_{b}$ : flow rate of base and $\mathrm{x}_{2}: \Delta \theta$ : temperate variation. The corresponding output of input $x_{j}$ at node (i) in Layer (1) is $\mathrm{O}^{1}{ }_{i, j}$. Layer 1 contains $\mathrm{k}$ nodes for every input which correspond to Bell Membership Functions (BMF) according to:

$$
\mathrm{O}_{\mathrm{i}, \mathrm{j}}^{1}=\mu_{\mathrm{Ai,j}}\left(\mathrm{x}_{\mathrm{j}}\right), \mathrm{i}=1,2, \ldots, \mathrm{k}, \mathrm{j}=1,2
$$

Where:

$\mathrm{A}_{\mathrm{i}, \mathrm{j}}=$ Fuzzy sets describing the input

$\mu_{\mathrm{A} i \mathrm{j},}\left(\mathrm{x}_{\mathrm{j}}\right)=$ The degree of membership of a variable $\mathrm{x}_{\mathrm{j}}$ into the fuzzy set $A_{i, j}$

To calculate the firing strength of the mth rule (total $\mathrm{n}$ rules) in Layer $2, \mathrm{w}_{\mathrm{m}}$ the rule output is equal to the product of incoming inputs from Layer 1 :

$$
\mathrm{O}_{\mathrm{m}}^{2}=\mathrm{w}_{\mathrm{m}}=\prod_{\mathrm{m}=\mathbb{1}}^{\mathrm{n}} \mu_{\mathrm{A}, \mathrm{j}}\left(\mathrm{x}_{\mathrm{j}}\right)
$$

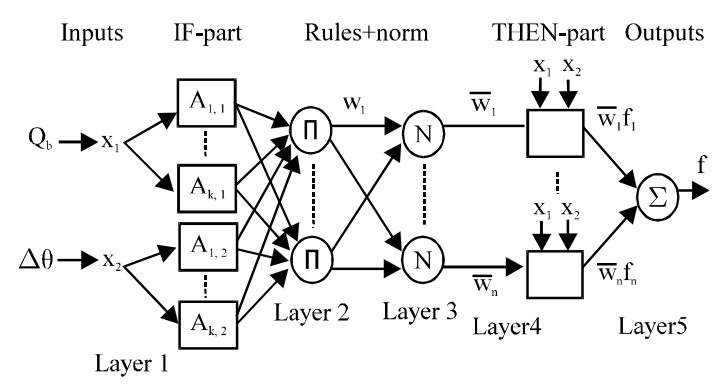

Fig. 4: Architecture of the Adaptive Neuro-Fuzzy System 
$i, j$ are defined in mth rule. The process continues to Layer 3 , the mth node computes the ratio of the mth rule's firing strength to the sum of firing strength (normalization):

$$
\mathrm{O}_{\mathrm{m}}^{3}=\overline{\mathrm{W}}_{\mathrm{m}}=\frac{\mathrm{w}_{\mathrm{m}}}{\sum_{\mathrm{m}=1}^{\mathrm{n}} \mathrm{w}_{\mathrm{m}}}
$$

In Layer 4 each node in this layer represents a rule; it has adaptive nodes with corresponding functions:

$$
\mathrm{O}_{\mathrm{m}}^{4}=\overline{\mathrm{W}}_{\mathrm{m}} \times \mathrm{f}_{\mathrm{m}}
$$

where, $f_{m}$ is a crisp variable of $m$ th rule that describes the output. The last Layer 5 has a single node which computes the output (indentation loads) as the summation of Layer 4 outputs:

$$
\mathrm{O}_{1}^{5}=\sum_{\mathrm{m}=1}^{\mathrm{n}} \overline{\mathrm{W}}_{\mathrm{m}} \times \mathrm{f}_{\mathrm{m}}
$$

The implemented learning algorithms involve unsupervised learning of the BMF (centers and widths) followed by unsupervised learning of the rules (calculation of rules and updates) and error back propagation for optimization of the membership functions (the output and the error are fed back to Layer 2). Different data sets were used to validate the accuracy of the model.

The designed observer is validated experimentally to determine $\mathrm{pH}$ values (as a process variable in the control scheme) through measuring of $Q_{b}$ (as a manipulated variable in control scheme). To examine the designed observer, the estimated $\mathrm{pH}$ values were compared with experimental results to find the absolute average testing error which was about 0.019 as shown in Fig. 5.

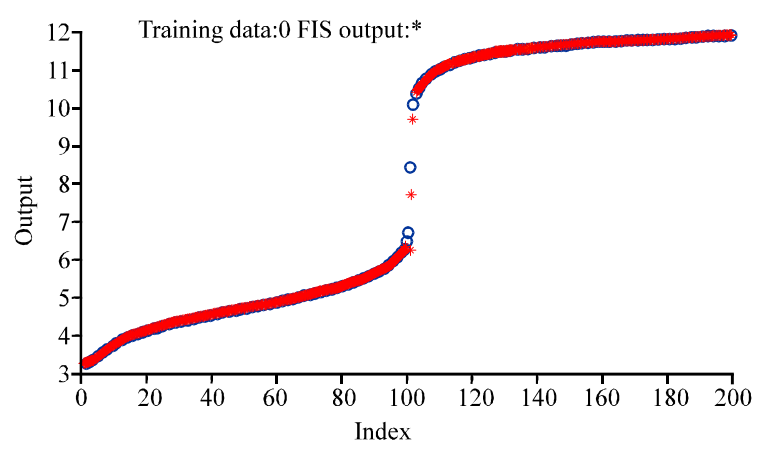

Fig. 5: Observed $\mathrm{pH}$ values (o) Training data, (*) FIS output. Scaling factor at $\mathrm{x}$-axis is 0.01
Finally, the designed and validated observer is employed in the feedback design of the control loop as shown in Fig. 1.

\section{MULTIREGIONAL FUZZY-BASED CASCADE CONTROL STRUCTURE}

The cascade control structure is very common in chemical processes. The proposed multiregional fuzzybased cascade control structure shown in Fig. 1, consists of two main loops: the master loop (outer loop) where multiregional fuzzy PI controller is used and the slave loop (inner loop) where a Weiner Model-based fuzzy P controller is implemented, these interacting loops work together to obtain the optimal control over the process.

In the case of strong acid system, the nonlinear gain of the process output will be canceled out with the inversed function of the process (shown in Fig. 1 which uses a constant $\mathrm{K}_{\mathrm{a}}$ of infinity for a strong acid) and accordingly the process control is achieved within the inner loop. Although, in a case of a weak acid system, the process output gain will not be canceled out completely with the inverse function and therefore, the residue will be corrected within the outer loop. The proposed fuzzy controller will overcome the nonlinearity of the titration curve by partitioning the titration curve into three main regions (Henson and Seborg, 1994). The multiregional fuzzy controller will behave according to the determined region.

The controller has three inputs and only one output making the system as a Multi-Inputs Single-Output System (MISO). The inputs are: the error signal e, the error difference $\Delta \mathrm{e}$ and an Auxiliary Variable (AV) which is control input that expresses the three regions of the titration curve while the output is the actuating signal expressing $\left(\Delta \mathrm{Q}_{\mathrm{b}}\right)$. The membership functions of each input and output is shown in Fig. 6.

The inputs of $\mathrm{e}$ and $\Delta \mathrm{e}$ consists of five triangular membership functions ranging between -1 and 1 while the third control input AV is expressed with three trapezoidal membership functions. It's representing the three regions of the titration curve ranging between 0 and 13. The output is more complicated than the inputs structure, it is represented using twelve triangular membership functions with seven main functions that is used to perform the aggressive variations needed during control while the other five functions used for the fine control actions, the output's membership functions are ranging between -1 and 1 . The rules set of this controller are shown in Table 1 and 2 . The response of the multiregional controller within the three regions of the titration curve and towards the set point tracking is shown in Fig. 7 and 8. 

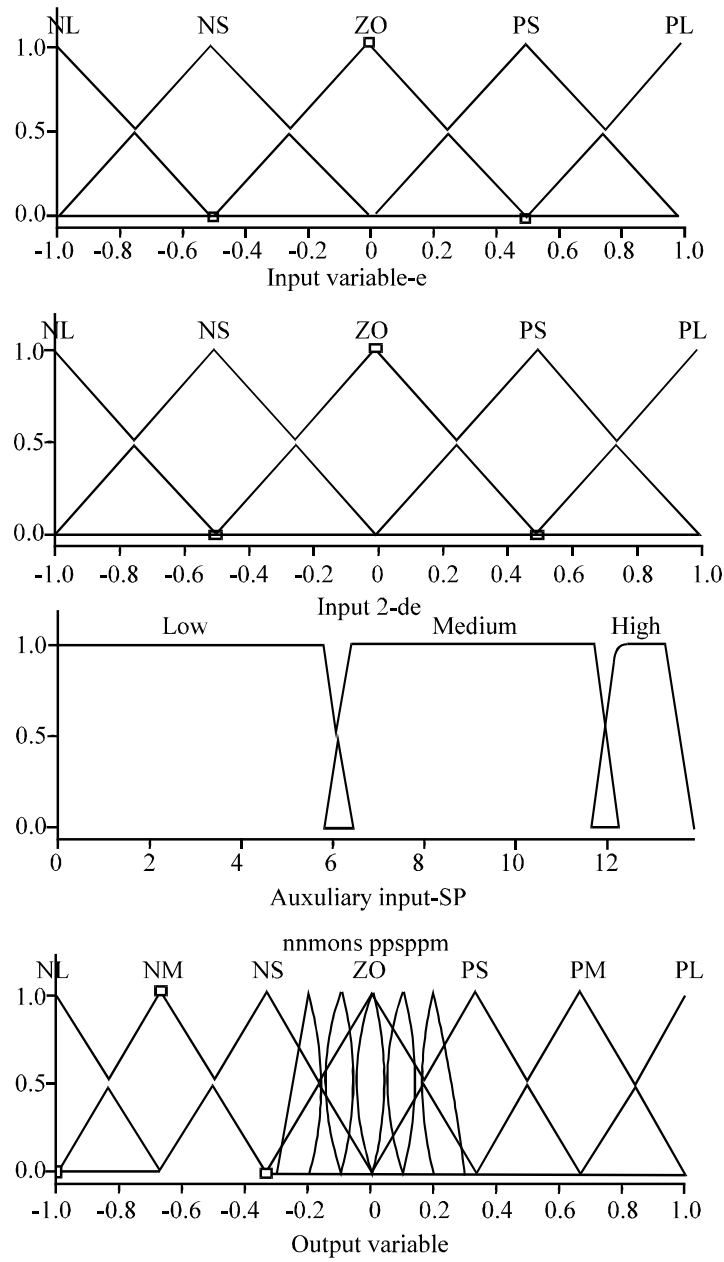

Fig. 6: Membership functions of inputs and outputs of the multiregional fuzzy controller

Table 1: Rules set of multiregional fuzzy controller if AV is high or low for linear regions with titration curve

\begin{tabular}{llllll}
\hline e\} \Delta \mathrm { e } $&{\text { NL }} &{\text { NS }} &{\text { ZO }} &{\text { PS }} &{\text { PL }} \\
{\hline \text { NL }} &{\text { PL }} &{\text { PL }} &{\text { PL }} &{\text { PM }} &{\text { ZO }} \\
{\text { NS }} &{\text { PL }} &{\text { PL }} &{\text { PM }} &{\text { ZO }} &{\text { NM }} \\
{\text { ZO }} &{\text { PM }} &{\text { PM }} &{\text { ZO }} &{\text { NM }} &{\text { NL }} \\
{\text { PS }} &{\text { PS }} &{\text { ZO }} &{\text { NM }} &{\text { NL }} &{\text { NL }} \\
{\text { PL }} &{\text { PL }} &{\text { NS }} &{\text { NM }} &{\text { NL }} &{\text { NL }}$
\end{tabular}

Table 2: Rules set of multiregional fuzzy controller if AV is medium for highly nonlinear region

\begin{tabular}{|c|c|c|c|c|c|}
\hline $\mathrm{e} \Delta \mathrm{e}$ & $\mathrm{NL}$ & $\mathrm{NS}$ & $\mathrm{ZO}$ & PS & $\mathrm{PL}$ \\
\hline$\overline{N L}$ & PM & PS & $\mathrm{Ppm}$ & Pps & Zzo \\
\hline NS & Ppm & Pps & Pps & Zzo & Nns \\
\hline $\mathrm{ZO}$ & Pps & Pps & Pps & Nns & Nns \\
\hline PS & Pps & Zzo & Zzo & Nns & Nnm \\
\hline$\underline{\mathrm{PL}}$ & Zzo & Nns & $\mathrm{Nnm}$ & NS & $\mathrm{NM}$ \\
\hline
\end{tabular}

Figure 7 and 8 clearly show a superior performance of the multiregional fuzzy-based cascade controller over the titration process with minimal resulted errors. The
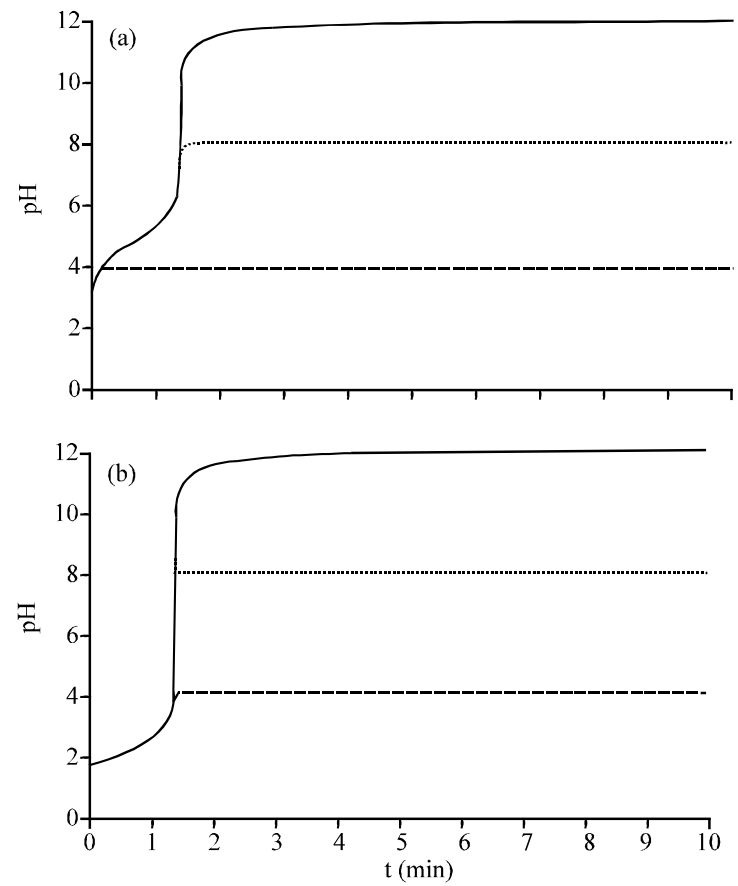

Fig. 7: Performance of closed loop structure with multiregional fuzzy controller in set point tracking;

a) for weak acid and b) for strong acid
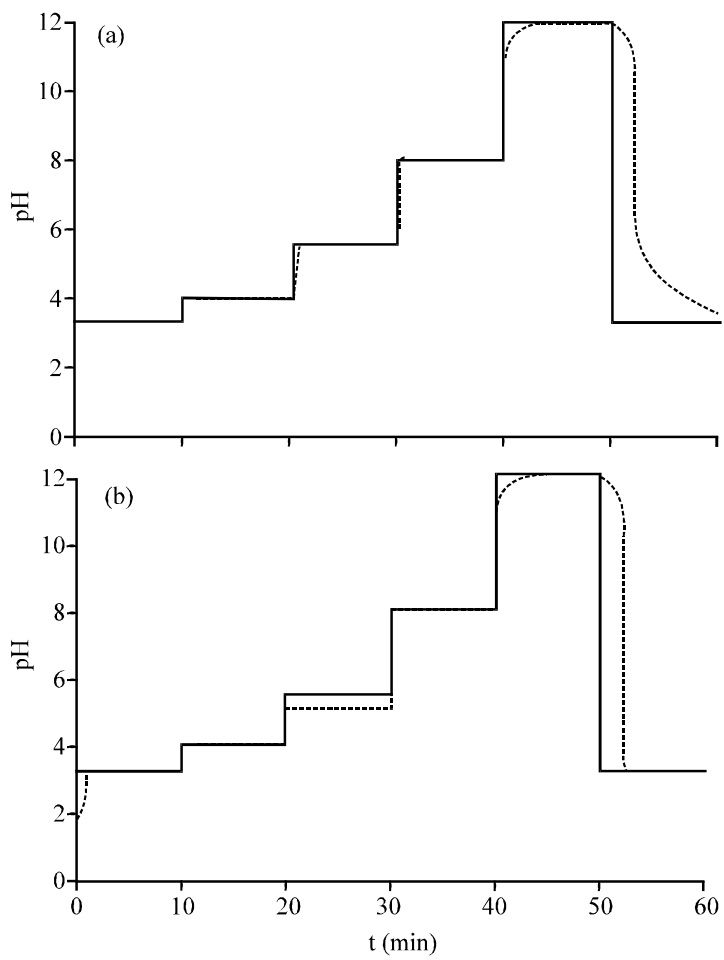

Fig. 8: Performance of control structure with multiregional fuzzy controller in the three regions of titration curve; a) for weak acid and b) for strong acid 
proposed cascade control structure uses two fuzzy-based controllers (in master and slave loops Fig. 1), each behaves differently to obtain the improved response shown in Fig. 8.

\section{CONCLUSION}

The troubles might be found with $\mathrm{pH}$ electrodes, used for $\mathrm{pH}$ measurements have been resolved by proposing an ANFIS-based $\mathrm{pH}$ observer that if implemented experimentally will optimize the size of overall plant with cost reduction to meet the industrial enquiries. And this is one of perspectives of the present research. The effectiveness of the proposed observer has been ensured as well concluded when comparing Fig. 2 with Fig. 5. On the control side of this study, the nonlinear behavior exhibited by the $\mathrm{pH}$ process was tested using nonlinear intelligent-based cascade control. It proved to be the best technique that could be used with such systems comparing with other nonlinear classical cascade ones that suffering from problems of parameter tuning.

\section{REFERENCES}

Gulaian, M. and J. Lane, 1990. Titration curve estimation for adaptive $\mathrm{pH}$ control. Proceedings of the American Control Conference, May 23-25, San Diego, CA., pp: 1414-1419.

Guner, E., 2003. Adaptive neuro fuzzy inference system applications in chemical processes. Master of Science, Middle East Technical University, Ankara.
Gupta, R.A., R. Kumar and R.S. Surjuse, 2009. ANFIS based intelligent control of vector controlled induction motor drive. Proceedings of the 2nd International Conference on Emerging Trends in Engineering and Technology, Dec. 16-18, Nagpur, India, pp: 674-680.

Henson, M.A. and D.E. Seborg, 1994. Adaptive nonlinear control of a $\mathrm{pH}$ neutralization process. IEEE Trans. Control Syst. Technol., 2: 169-182.

Luyben, W.L., 1989. Process Modeling, Simulation and Control for Chemical Engineers. McGraw-Hill, Ohio.

Magada, L.O., 2008. Multivariate statistical process control and case-based reasoning for situation assessment of sequencing batch reactor. Ph.D. Thesis, Universitat de Girona Catalonia.

Ogunnaik, B.A. and W.H. Ray, 1994. Process Dynamics, Modeling and Control. Oxford University Press, UK.

Parekh, M., M. Desai, H. Li and R.R. Rhinehart, 1994. Inline control of nonlinear $\mathrm{pH}$ neutralization based on fuzzy logic. IEEE Trans. Components, Packag. Manuf. Technol. A, 17: 192-201.

Pishvaie, M.R. and M. Shahrokhi, 2006. Control of pH processes using fuzzy modeling of titration curve. Fuzzy Sets Syst., 157: 2983-3006.

Qin, S.J. and G. Borders, 1994. A multi-region fuzzy logic controller for nonlinear process control. Proc. IEEE Trans. Fuzzy Syst., 2: 74-81.

Shinskey, F.G., 1974. Adaptive pH controller monitor nonlinear process. Control Eng., 21: 57-60.

Vojtesek, J. and P. Dostal, 2005. From steady-state and dynamic analysis to adaptive control of the CSTR reactor. Proceedings of the 19th European Conference on Modeling and Simulation, June 1-4, Riga, Latvia, pp: 591-598. 